\title{
Effect of Micropore Structure on Macroscopic Water Cut Changing Law in Strongly Heterogeneous Reservoirs
}

\author{
Renfeng Yang $\mathbb{D},,^{1,2}$ Ruizhong Jiang $\mathbb{D},{ }^{1}$ Guangwei Liu $\left(\mathbb{D},{ }^{3}\right.$ Han Chen $\mathbb{D}^{3},{ }^{3}$ Peiyuan Chen $\left(\mathbb{D},,^{3}\right.$ \\ and Zhaobo Sun $(10)^{3}$ \\ ${ }^{1}$ China University of Petroleum (East China), Qingdao 266580, China \\ ${ }^{2}$ CNOOC Research Institute Co., Ltd., No. 6, Taiyang Gong South Street, Chaoyang District, Beijing 100028, China \\ ${ }^{3}$ CNOOC International Co., Ltd., No. 6, Taiyang Gong South Street, Chaoyang District, Beijing 100028, China
}

Correspondence should be addressed to Renfeng Yang; yrf723@163.com

Received 4 September 2020; Revised 25 October 2020; Accepted 30 October 2020; Published 18 November 2020

Academic Editor: Guanglong Sheng

Copyright (C) 2020 Renfeng Yang et al. This is an open access article distributed under the Creative Commons Attribution License, which permits unrestricted use, distribution, and reproduction in any medium, provided the original work is properly cited.

\begin{abstract}
Reservoir rock type (RRT) classification is commonly used for the fine characterization of strongly heterogeneous reservoirs. Many research focused on proposing different RRT methods, while few studies focused on the relationship between micropore structure and macroscopic seepage law of fluid transporting through different types of formation. Considering the different diagenesis degrees of rock types in different sedimentary facies, the quadrant unit method and FZI method were applied to classify and evaluate the strongly heterogeneous reservoirs. The corresponding capillary pressure curves and relative permeability curves for different rock types could be obtained. A set of theoretical models that could describe the macroscopic seepage law are proposed, and numerical simulation case studies were carried out to explore the superimposed seepage law in reservoirs under different degrees of heterogeneity. Results show that water cut rises faster in poor-property RRT formation than in goodproperty RRT formation, with a lower recovery factor under the same conditions. The water cut rising rate increases firstly and then decreases with water cut and recovery degree increasing. The poorer the rock property is, the earlier and higher the peak value of water cut rising rate is. Also, based on numerical simulation case studies, the superimposed seepage law is close to that in the poor-property formation as the heterogeneity degree strengthens. The newly proposed method not only could provide a reference for rock type classification based on micropore structure but also could expound the influence of micropore structure on the change law of macroscopic water cut and elaborates the macroscopic change law after the superposition of different types of reservoirs. The conventional normalization of relative permeability curves is only applicable to relatively homogeneous reservoirs and not applicable to strongly heterogeneous reservoirs, especially when the permeability variation is higher than 0.7 . The newly proposed approach is capable of analyzing the effect of micropore structure on macroscopic seepage law and improving the prediction accuracy of the production profile.
\end{abstract}

\section{Introduction}

At present, most of the reservoirs in the world are strongly heterogeneous, and the permeability variation could be very large with poor porosity-permeability relationship. In order to improve production profile forecasting accuracy, RRT classification is one of the most important reservoir characterization processes, which is also essential for high accurate dynamic simulation and reliable predictions. Many scholars conducted extensive research on RRT classification and pro- posed many methods such as the capillary pressure method, Leverett dimensionless J-function method, Winland R35 method, reservoir quality factor (RQI) method, and flow zone indicator (FZI) [1-3]. Although these studies provide guidance for fine formation characterization, few research has been carried out to study the relationship between micropore structure and seepage law for different RRT, resulting in unclear understanding of seepage law of strongly heterogeneous reservoirs and difficulties in making corresponding adjustment measures in different development stages. 
There are several methods to study micropore structure, including the capillary pressure curve method [4-6], image analysis method $[7,8]$, three-dimensional pore structure simulation method [9-12], and well logging method [13-15]. For the capillary pressure curve method, capillary pressure was experimented quantitatively through experiments to judge pore throat size, distribution, connectivity, and so on. Fractal dimension was sometimes incorporated to characterize micropore structure which could improve the quantitative prediction. The image analysis method includes casting thin section observation, Scanning Electron Microscopy (SEM), and CT scan imaging, by which core samples and thin sections could be observed directly to obtain characteristics of micropores. But there are some limitations such as narrow observation range and high cost. The three-dimensional pore structure simulation method needs input of microstructure characterization from image analysis. After that, a pore space was reconstructed by using the Gaussian distribution method [9], the simulated annealing method [10], the processing method [11], and so on. However, the application range was limited to high cost and simulation scale. The well logging method could be used for micropore structure research through nuclear magnetic resonance (NMR), resistivity well logging, and acoustic well logging.

Based on the above-mentioned methods, micropore structure could be characterized effectively through introducing parameters such as the pore-throat ratio, coordination number, pore geometry factor, microhomogeneous factor, threshold pressure, pore relative sorting coefficient, throat relative sorting coefficient, and surface volume ratio. However, these parameters could characterize pore structure from the microlevel and cannot completely reflect the real core pore's complexity and heterogeneity. Moreover, due to numerous parameters, it is difficult to predict the production profile from a macrolevel. Yet, the fractal geometry could reflect the microscopic parameters to a certain extent, and it is equivalent to integrating the above-mentioned microscopic parameters, greatly reducing the number of parameters, which lays the foundation for the analysis of macroscopic seepage laws [16, 17]. Pfeifer and Avnir [18] concluded that the pore size distribution was fractal by using an adsorbent. Katz and Thompson [19] studied the relationship between fractal dimension and conductivity. Krohn [20, 21] presented experimental evidence indicating that the pore spaces of sandstone/shale/carbonate samples are fractal, and the range of fractal dimension is from 2.27 to 2.89 with pore radii $0.2 \sim 50 \mu \mathrm{m}$. Angulo et al. [22] indicated that the numerical values of fractal dimension of pore structure, pore-rock interfaces, and pore bulk seemed to be particular with a quite wide variation range. Jia et al. [16] proposed the lower limit of fractal dimension for pore structure of sandstone. Afterwards, many scholars $[16,23,24]$ obtained fractal dimensions of pore structure for different lithology by combining mercury injection data, SEM, and thin section; then, the reservoir can be fine described.

By combining micropore structure and other geological characteristics, the reservoir rock type can be defined [2527], which could be applied to constructing a fine geological model. Micropore structure also can be used to characterize areal heterogeneity and vertical heterogeneity [28] and then further to predict interwell reservoir properties [24, 29], define the remaining oil distribution and morphology, explore its influence on the water flooding efficiency qualitatively $[30,31]$, and predict core scale drainage efficiency for different micropore structures. Other scholars [32-37] attempt to evaluate the impact of micropore structure on oil production potential, recovery factor, and dynamic performance from the point of micropore structure's influence on macrooilfield development rules. In summary, the above-mentioned studies focused on qualitative analysis but not on quantitative analysis. Wang et al. [38] studied change rules of reservoir property and fractal dimensions and concluded that the fractal dimensions were changing along with water cut rising. Thus, dynamic performance of only increasing the liquid production rate was not so good, with water plugging, and profile control should simultaneously be conducted to improve production performance. This paper did not discuss the influence of different micropore structures on macrseepage law.

Although reservoir numerical simulation is one of the widely used methods for production profile prediction of a heterogeneous reservoir, the time-consuming history matching and heavy work load lead to some limitations during the application process, especially while the history matching results were not satisfied. The relative permeability curves were often used for production profile forecast after normalization. However, the normalized relative permeability curve is only applicable to relatively homogeneous reservoirs and not applicable to strongly heterogeneous reservoirs. Some scholars discussed the solution for predicting the production profile of strongly heterogeneous reservoirs through RRT classification, but none of them has given the critical conditions. In this paper, the reasons why the micropore structure in different rock type reservoirs was quite different and the characteristics of the capillary pressure and relative permeability curves of different rock type reservoirs were further analyzed. A set of theoretical models to quantitatively analyze the seepage law of fluid transporting through different rock types and the correspondence between macroscopic seepage law and micropore structure were clarified. The influence level of different RRT on macroscopic seepage flow law was systematically analyzed, and the critical conditions for relative permeability classification were clarified. In addition, the influence law and superposition effect of different RRT on macroscopic seepage law were further discussed.

\section{Theoretical Analysis and Analytical Models}

The relative permeability curve is a bridge connecting the microparameters with the macroscopic seepage law. Based on the theoretical expression of the relative permeability curve, the relationship between the micropore structure parameters and the macroscopic seepage parameters was established, and the macroscopic water cut, water cut rising rate, dimensionless oil/fluid index, and theoretical model of recovery efficiency were further derived theoretically, which laid a foundation for the subsequent discussion on the 
influence of the micropore structure on the macroscopic seepage law.

2.1. Water Cut Changing Theoretical Model. The oil-water relative permeability curves could be expressed as follows:

$$
\begin{gathered}
K_{\mathrm{ro}}\left(S_{\mathrm{we}}\right)=\left(1-\frac{S_{\mathrm{we}}-S_{\mathrm{wc}}}{1-S_{\mathrm{wc}}-S_{\mathrm{or}}}\right)^{2} \cdot\left[1-\left(\frac{S_{\mathrm{we}}-S_{\mathrm{wc}}}{1-S_{\mathrm{wc}}-S_{\mathrm{or}}}\right)^{\left(3-D_{\mathrm{h}}\right) /\left(3-D_{\mathrm{c}}\right)}\right] \\
K_{\mathrm{rw}}\left(S_{\mathrm{we}}\right)=K_{\mathrm{rw}}\left(S_{\mathrm{or}}\right)\left(\frac{S_{\mathrm{we}}-S_{\mathrm{wc}}}{1-S_{\mathrm{wc}}-S_{\mathrm{or}}}\right)^{\left(\left(3-D_{\mathrm{h}}\right) /\left(3-D_{\mathrm{c}}\right)\right)+2},
\end{gathered}
$$

while

$$
S_{\mathrm{wd}}=\frac{S_{\mathrm{we}}-S_{\mathrm{wi}}}{1-S_{\mathrm{wi}}-S_{\mathrm{or}}}
$$

According to the fractional flow equation, the water cut could be expressed as follows:

$$
f_{\mathrm{w}}=\frac{1}{1+\left(\mu_{\mathrm{w}} B_{\mathrm{w}} / \mu_{\mathrm{o}} B_{\mathrm{o}}\right)\left(K_{\mathrm{ro}} / K_{\mathrm{rw}}\right)} .
$$

Substitute Equations (1) and (2) into Equation (4).

$$
f_{\mathrm{w}}=\frac{1}{1+\left(\mu_{\mathrm{w}} B_{\mathrm{w}} / \mu_{\mathrm{o}} B_{\mathrm{o}}\right)\left(\left(\left(1-\left(\left(S_{\mathrm{we}}-S_{\mathrm{wc}}\right) /\left(1-S_{\mathrm{wc}}-S_{\mathrm{or}}\right)\right)\right)^{2} \cdot\left[1-\left(\left(S_{\mathrm{we}}-S_{\mathrm{wc}}\right) / 1-S_{\mathrm{wc}}-S_{\mathrm{or}}\right)^{\left(3-D_{\mathrm{h}}\right) /\left(3-D_{\mathrm{c}}\right)}\right]\right) / K_{\mathrm{rw}}\left(S_{\mathrm{or}}\right)\left(\left(S_{\mathrm{we}}-S_{\mathrm{wc}}\right) /\left(1-S_{\mathrm{wc}}-S_{\mathrm{or}}\right)\right)^{\left(\left(3-D_{\mathrm{h}}\right) /\left(3-D_{\mathrm{c}}\right)\right)+2}\right)} .
$$

Equation (5) is the theoretical calculation model of macroscopic water cut varying with water saturation. It depends on the oil-water viscosity ratio, relative permeability curve (irreducible water saturation, residual oil saturation, and maximum water phase relative permeability), and micropore-throat structure parameters. A clear quantitative relationship between water saturation and micropore structure was established for the first time.

The average water saturation could be expressed by Equation (6) through theoretical derivation [39-41].

$$
\bar{S}_{\mathrm{w}}=\omega S_{\mathrm{we}}+(1-\omega)\left(1-S_{\mathrm{or}}\right) .
$$

The recovery of recoverable reserves could be presented as follows:

$$
R_{\mathrm{f}}=\frac{\bar{S}_{\mathrm{w}}-S_{\mathrm{wi}}}{1-S_{\mathrm{wi}}-S_{\mathrm{or}}}=\omega S_{\mathrm{wd}}+(1-\omega)
$$

if

$$
\begin{gathered}
M=\frac{\mu_{\mathrm{o}} B_{\mathrm{o}} K_{\mathrm{rw}}\left(S_{\mathrm{or}}\right)}{\mu_{\mathrm{w}} B_{\mathrm{w}} K_{\mathrm{ro}}\left(S_{\mathrm{wi}}\right)}, \\
\lambda=\frac{3-D_{\mathrm{h}}}{3-D_{\mathrm{c}}} .
\end{gathered}
$$

Then, the relationship between water cut and the recovery of recoverable reserves could be obtained:

$$
f_{\mathrm{w}}=\frac{M\left(R_{\mathrm{f}}+\omega-1\right)^{\lambda+2}}{\left(1-R_{\mathrm{f}}\right)^{2}\left[\omega^{\lambda}-\left(R_{\mathrm{f}}+\omega-1\right)^{\lambda}\right]+M\left(R_{\mathrm{f}}+\omega-1\right)^{\lambda+2}} .
$$

The quantitative function relationship between water saturation and the recovery degree of recoverable reserves is established in Equation (10) with the influence parameters such as the oil-water viscosity ratio, Welge coefficient, and micropore-throat structure parameters.

2.2. Water Cut Rising Rate Theoretical Model. The water cut rising rate is defined as water cut rising amplitude producing $1 \%$ recoverable reserves [40]:

$$
f_{\mathrm{w}}^{\prime}=\frac{d f_{\mathrm{w}}}{d R_{\mathrm{f}}}
$$

The following equation can be obtained by the derivative of Equation (10)

$$
\frac{d f_{\mathrm{w}}}{d R_{\mathrm{f}}}=\frac{M\left(1-R_{\mathrm{f}}\right)\left(\left(R_{\mathrm{f}}+\omega-1\right)^{\lambda+1} / \omega^{\lambda+1}\right)\left[(\lambda / \omega)\left(1-R_{\mathrm{f}}\right)+2-2\left(\left(R_{\mathrm{f}}+\omega-1\right)^{\lambda} / \omega^{\lambda}\right)\right]}{\left[\left(1-R_{\mathrm{f}}\right)^{2}-\left(1-R_{\mathrm{f}}\right)^{2}\left(\left(R_{\mathrm{f}}+\omega-1\right)^{\lambda} / \omega^{\lambda}\right)+M\left(\left(R_{\mathrm{f}}+\omega-1\right)^{\lambda+2} / \omega^{\lambda}\right)\right]^{2}} .
$$


The quantitative relationship between the water cut increasing rate and the recovery degree of recoverable reserves is established in Equation (12) and is influenced by the oil-water viscosity ratio, Welge coefficient, and micropore-throat structure parameters.

2.3. Dimensionless Oil Production Index and Liquid Production Index. The dimensionless oil production index refers to the ratio of the current oil productivity to the initial oil productivity, i.e.,

$$
J_{\mathrm{DO}}=\frac{K_{\mathrm{ro}}}{K_{\mathrm{ro}}\left(S_{\mathrm{wi}}\right)} .
$$

Substitute Equation (1) into Equation (13):

$$
J_{\mathrm{DO}}=\left(1-S_{\mathrm{wd}}\right)^{2} \cdot\left(1-S_{\mathrm{wd}}^{\lambda}\right) \text {. }
$$

It could be seen from Equation (14) that the relationship between the dimensionless oil production index and the water saturation is only influenced by the micropore structure. The dimensionless liquid production index refers to the ratio of the current liquid productivity to the initial fluid productivity, i.e.,

$$
J_{\mathrm{DL}}=\frac{K_{\mathrm{ro}}}{K_{\mathrm{ro}}\left(S_{\mathrm{wi}}\right)}+\frac{K_{\mathrm{rw}} B_{\mathrm{o}} \mu_{\mathrm{o}}}{K_{\mathrm{ro}}\left(S_{\mathrm{wi}}\right) B_{\mathrm{w}} \mu_{\mathrm{w}}} .
$$

Substitute Equation (1) into Equation (15):

$$
J_{\mathrm{DL}}=\left(1-S_{\mathrm{wd}}\right)^{2} \cdot\left(1-S_{\mathrm{wd}}^{\lambda}\right)+M S_{\mathrm{wd}}^{\lambda+2}
$$

It can be seen from Equation (16) that the relationship between the dimensionless liquid production index and the water saturation is influenced by both the micropore structure and the oil-water viscosity ratio.

2.4. Recovery Degree Model. The recovery factor under geological reserves could be calculated [42]:

$$
R_{\mathrm{fN}}=R_{\mathrm{f}} E_{\mathrm{A}} E_{\mathrm{Z}} E_{\mathrm{D}}
$$

The commonly used calculation methods of vertical and areal sweep efficiency are as follows [7]:

$$
\begin{gathered}
E_{\mathrm{A}}=\frac{1}{\left[a_{1} \ln \left(M+a_{2}\right)+a_{3}\right] f_{\mathrm{w}}+a_{4} \ln \left(M+a_{5}\right)+a_{6}+1}, \\
Y=b_{1} E_{\mathrm{Z}}^{b_{2}}\left(1-E_{\mathrm{Z}}\right)^{b_{3}} \\
Y=\frac{(\mathrm{WOR}+0.4)\left(18.948-2.499 V_{K}\right)}{\left(M+1.137-0.8094 V_{K}\right) 10^{f\left(V_{K}\right)}} \\
f\left(V_{K}\right)=-0.6891+0.9735 V_{K}+1.6453 V_{K}^{2} .
\end{gathered}
$$

The displacement efficiency could be calculated as follows:

$$
E_{\mathrm{D}}=\frac{1-S_{\mathrm{or}}-S_{\mathrm{wi}}}{1-S_{\mathrm{wi}}},
$$

where $a_{i}$ are coefficients related to the well pattern. For example, values of $a_{i}$ are $-0.2026,-0.0712,-0.511,0.3048,0.123$, and 0.4394 , respectively, for the five-spot well pattern (values for the nine-spot and line-drive well pattern could be obtained in Reference [43]). Also, $b_{1}=3.334, b_{2}=0.774$, and $b_{3}=-1.226$.

The relationship between the recovery degree and water cut could be calculated through Equations (17)-(22).

\section{Results and Discussions}

The analytical models presenting the relationship between micropore structure parameters and macroscopic seepage law have been established through theoretical derivation. The classification of capillary curves, relative permeability curves of different RRT, and the macroscopic seepage law could be discussed below taking the $\mathrm{X}$ carbonate oilfield in the Middle East as an example.

3.1. Differences in Micropore Structures of Different Rock Type Formation. The carbonate reservoir formation is featured with diversifying pore types, complex micropore structures, and poor porosity-permeability correlation, leading to strong heterogeneity because of the diagenesis influence. Based on microstructure characteristics, pore types, diagenesis, and genetic mechanism analysis, the influence of multiple factors is comprehensively taken into account, including inheritance relationship between lithology and sedimentary facies belt, modification effects of diagenesis, and differences in diagenesis degrees related to different rock types in various sedimentary facies belts. The quadrant method was chosen to classify the porous carbonate formation into 6 categories (see Figure 1).

(i) Type I reservoir: bioclastic beach/reef facies grainstones with well-developed gnamma holes and mold pore. Furthermore, the porosity and permeability are higher than $22 \%$ and $100 \mathrm{mD}$, respectively

(ii) Type II reservoir: bioclastic beach/reef facies grainstones with well-developed gnamma holes comparatively. In comparison with the type I reservoir, dissolution here is relatively poor. Furthermore, the porosity varies from $15 \%$ to $22 \%$, with permeability in the range of $10 \sim 100 \mathrm{mD}$ and higher than $100 \mathrm{mD}$ in a small amount of samples

(iii) Type III reservoir: shallow open marine facies packstone with comparatively developed gnamma holes. In spite of intense dissolution, the shaliness is higher than that in type I reservoir due to the influence of sedimentation. Moreover, the content of particles is comparatively lower. Furthermore, the porosity and permeability turn out to be $15 \sim 22 \%$ and $10 \sim 100 \mathrm{mD}$, respectively 

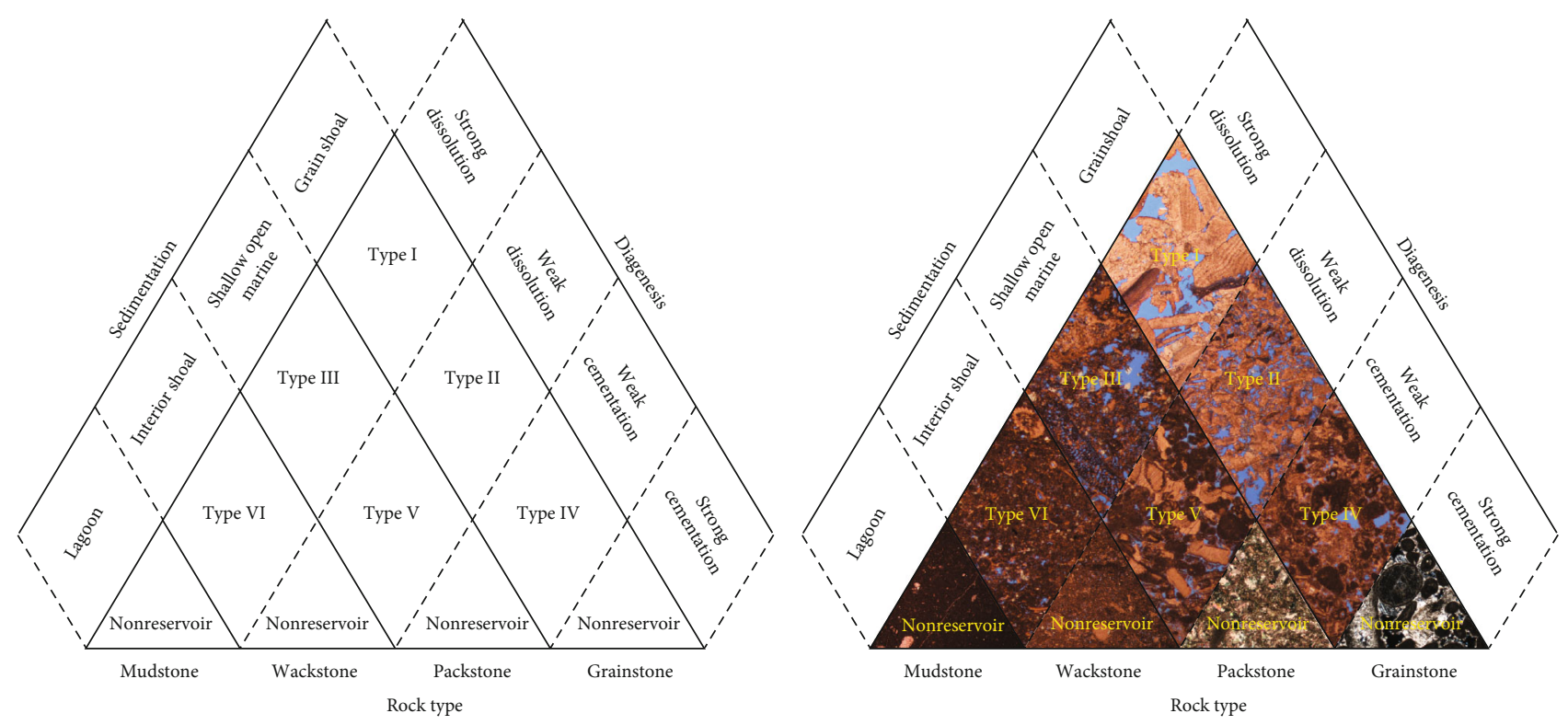

FIgURE 1: Classification of RRT in the X oilfield considering sedimentary facies and lithology.

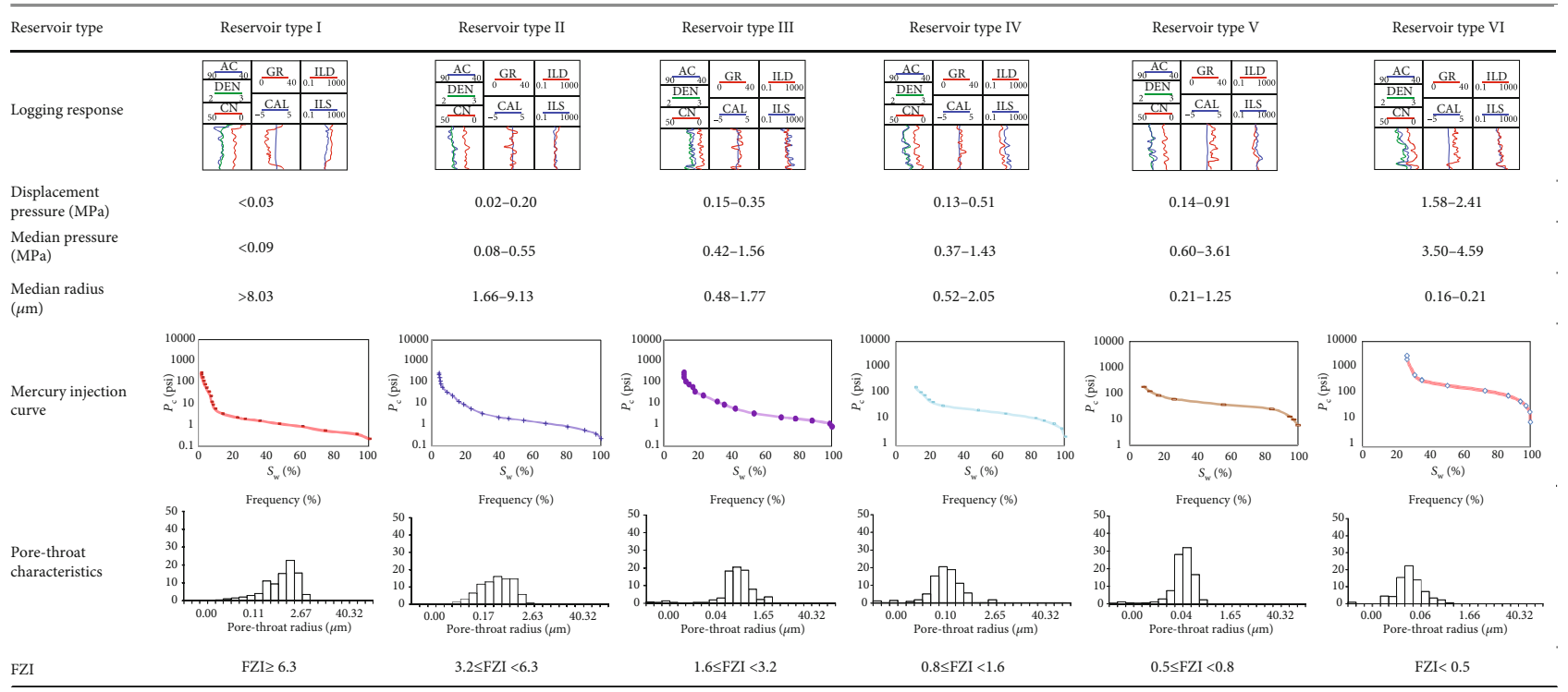

FIGURE 2: Logging curve responses and mercury injection curve characteristics of different RRT.

(iv) Type IV reservoir: bioclastic beach facies grainstones with lower developed pores. Under the influence of cementation, not only have primary intergranular pores been filled but also the reservoir physical property is also rather poor. Furthermore, the porosity and permeability are, respectively, lower than $15 \%$ and $10 \mathrm{mD}$

(v) Type V reservoir: shallow open marine facies packstone with relatively poor developed pores. The type $\mathrm{V}$ reservoir features poor dissolution and physical property. Furthermore, the porosity and permeability are lower than $15 \%$ and $10 \mathrm{mD}$, respectively (vi) Type VI reservoir: beach interact sea wackestone with pores undeveloped. Under the influence of strong dissolution, mold pores are locally developed, and the pore connectivity here is rather poor. Furthermore, the porosity and permeability are, respectively, lower than $10 \%$ and $1 \mathrm{mD}$

Based on geogenetic origin classification, the mercury injection curves, pore-throat distribution curves, and logging curves were further analyzed. Then, it could be concluded that pore-throat characteristics and flow zone indicator (FZI) of various reservoirs are proven to be significantly different, as shown in Figure 2. 


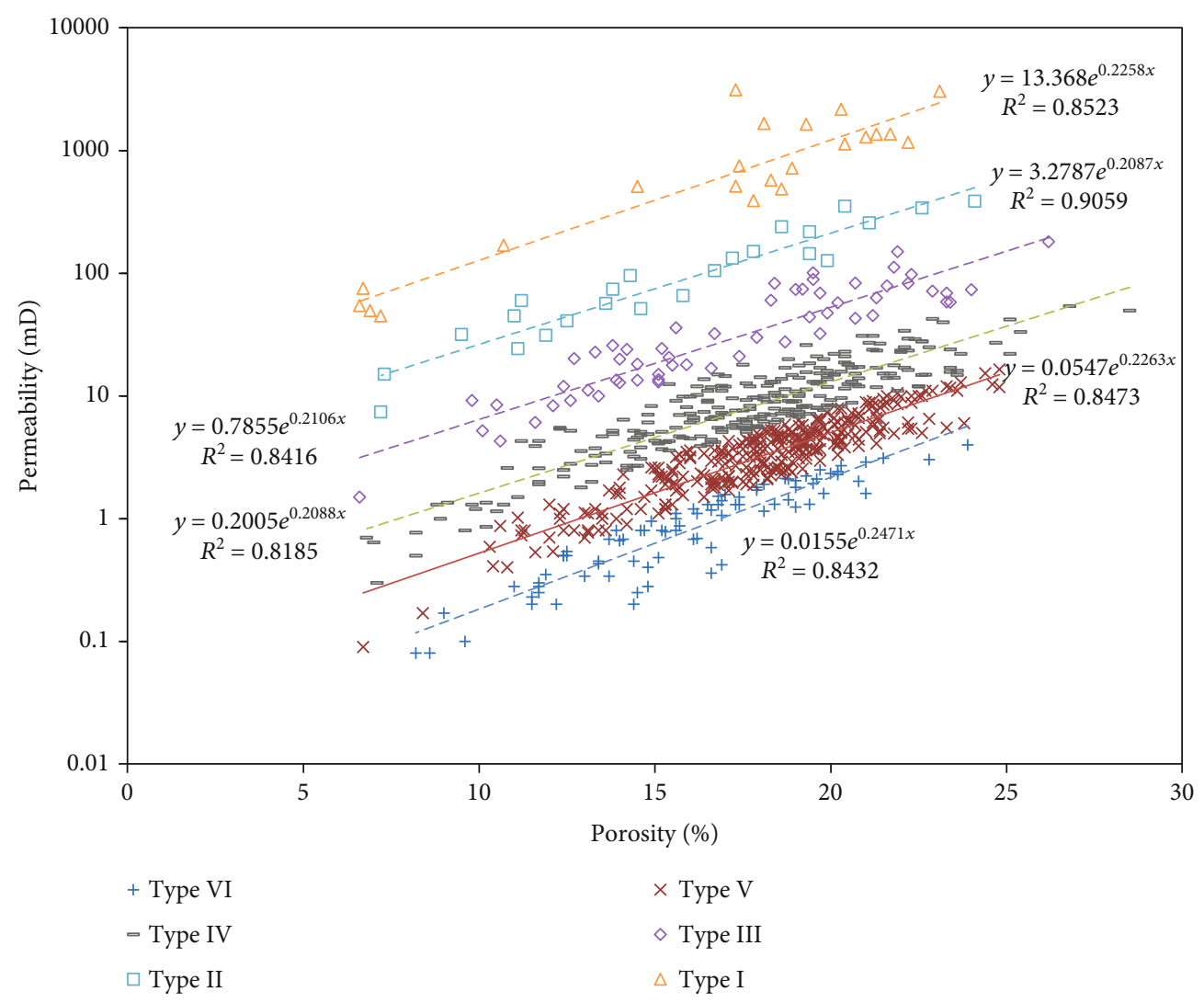

FIGURE 3: Porosity-permeability correlation of different RRT reservoirs.

As clarified above, FZIs of different rock type formation are significantly different from each other. The porosity and permeability are found to be preferably correlated among different RRT formation, which indicates the influence of micropore structures on the physical properties (see Figure 3).

Through analysis on capillary pressure curves of 42 core samples, it could be concluded that the characteristics of the capillary pressure curves in the same RRT were similar (see Figure 4). Considering the similarity of the capillary pressure curves characteristic of type I and type II, they could be merged into one category, so did type III and type IV. In this way, the original 6 categories of RRT could be simplified into 4 categories. Accordingly, $J$ functions could be finally summarized into 4 categories (see Table 1 ).

3.2. Relative Permeability Curves Characteristic of Different $R R T$. As mentioned above, different RRT were confirmed, and the corresponding relative permeability curves for different RRT (see Figure 5) should be analyzed based on core analysis. The influence of porous media parameters on relative permeability curves was determined through the interaction between rock and the fluid in porous media. Different lithology, different wettability, and the complexity of the pore structure may lead to a more complicated parametric variation trend. The physical parameters of porous media have a good correlation with the endpoint value parameters of the relative permeability curve, also including displacement effi- ciency. The better the physical property of the porous media, the lower the irreducible water saturation and residual oil saturation and the larger the maximum relative permeability of the wetting phase as well as the displacement efficiency.

It is indicated that the irreducible water saturation and residual oil saturation increase from RRT-1 to RRT-4, and the oil displacement efficiency decreases, as well as the relative permeability of the water phase under the residual oil saturation. The main reason is that the worse the reservoir physical properties, the higher the shale content, the lower the porosity and permeability, the worse the microporethroat connectivity, the larger the specific surface, and the larger the irreducible water saturation and residual oil saturation, resulting in an increase in the irreducible water saturation and residual oil saturation and a decrease in the maximum relative permeability of the wet phase under the residual oil saturation.

3.3. Macroscopic Seepage Law of Different RRT. The physical properties vary in a large range for strongly heterogeneous reservoirs, as well as the capillary curves and relative permeability curves for different RRT, resulting in great difference of water flooding seepage law. The seepage law of fluid transporting through different RRT formation should be studied on, and then, the overall seepage law could be analyzed, especially the influence degree, influence stage, and influence scope of different RRT formation. The seepage law in different RRT formation could be concluded taking the $\mathrm{X}$ actual 


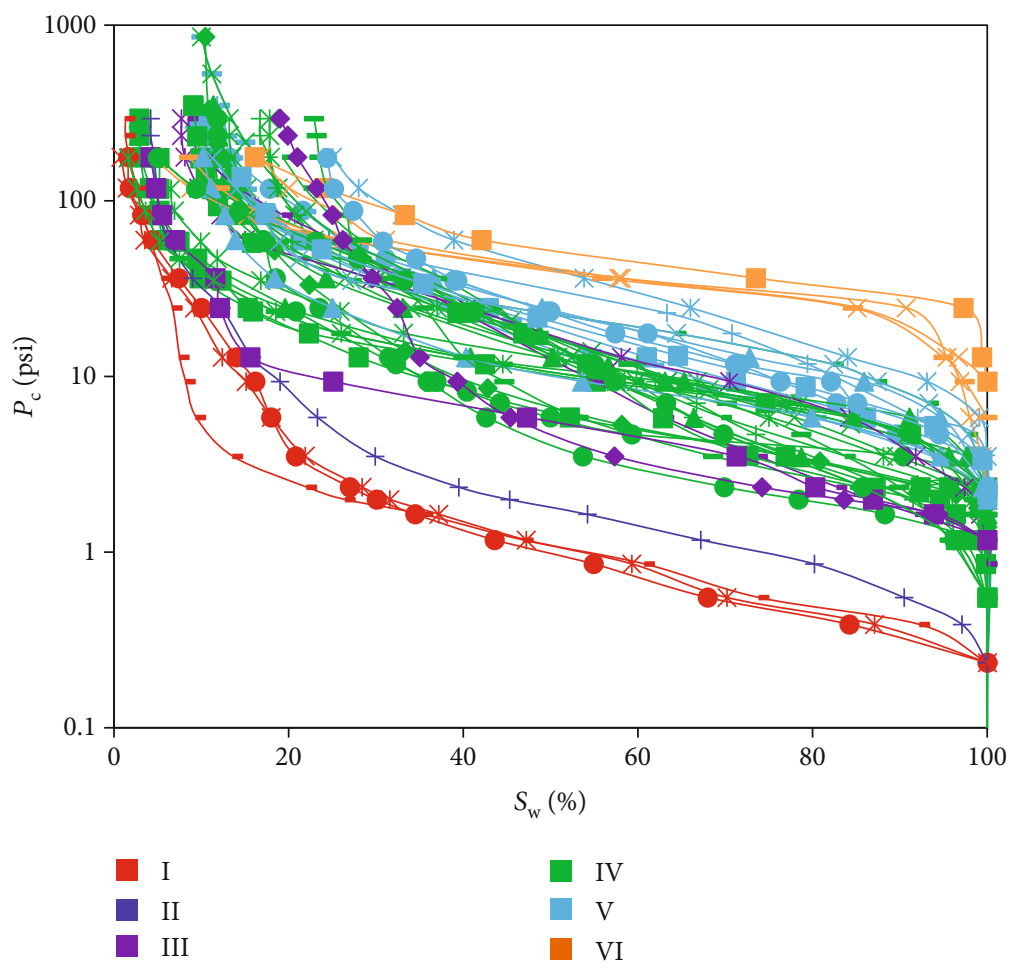

(a)

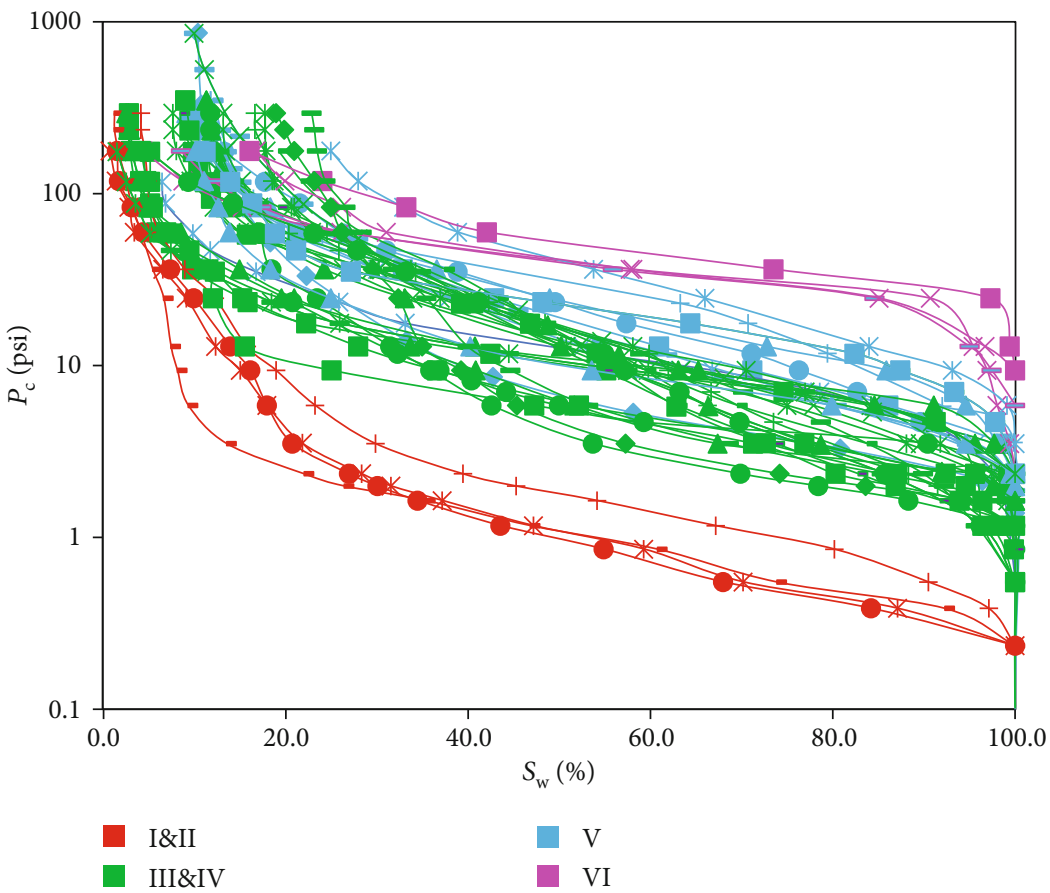

(b)

FIgURE 4: Capillary pressure curves for different formation.

carbonate oilfield in the Middle East as an example, as shown in Figures 6-10.

(i) Water cut rising rate changing law: the water cut rising rate curves present the following typical characteristics: increasing firstly and decreasing later along with recovery or water cut increase (see Figures 6 and 10). The worse the physical property of the reservoir, the earlier the peak of water cut increasing rate appears and the higher the peak. The main reason is that the worse the physical property of the reservoir, the lower the drivable oil saturation when 
TABLE 1: Porosity-permeability correlation and $J$ function of different RRT.

\begin{tabular}{lccc}
\hline Rock type & Distribution criteria & Permeability model & Relationship of $J$ function and water saturation $S_{\mathrm{w}}$ \\
\hline RT-I & $\mathrm{FZI} \geq 6.3$ & $K=13.368 e^{22.584 \varphi}, R^{2}=0.85$ & $J=142.98 S_{\mathrm{w}}-1.534, R^{2}=0.9482$ \\
RT-II & $3.2 \leq \mathrm{FZI}<6.3$ & $K=3.2787 e^{20.868 \varphi}, R^{2}=0.91$ & \\
RT-III & $1.6 \leq \mathrm{FZI}<3.2$ & $K=0.7855 e^{21.059 \varphi}, R^{2}=0.84$ & $J=162.7 S_{\mathrm{w}}-1.426, R^{2}=0.7551$ \\
RT-IV & $0.8 \leq \mathrm{FZI}<1.6$ & $K=0.2005 e^{20.884 \varphi}, R^{2}=0.82$ & $J=475.16 S_{\mathrm{w}}-1.742, R^{2}=0.7249$ \\
RT-V & $0.5 \leq \mathrm{FZI}<0.8$ & $K=0.0547 e^{22.632 \varphi}, R^{2}=0.85$ & $J=14.545 S_{\mathrm{w}}-0.813, R^{2}=0.7693$ \\
RT-VI & $\mathrm{FZI}<0.5$ & $K=0.0155 e^{24.713 \varphi}, R^{2}=0.84$ & \\
\hline
\end{tabular}

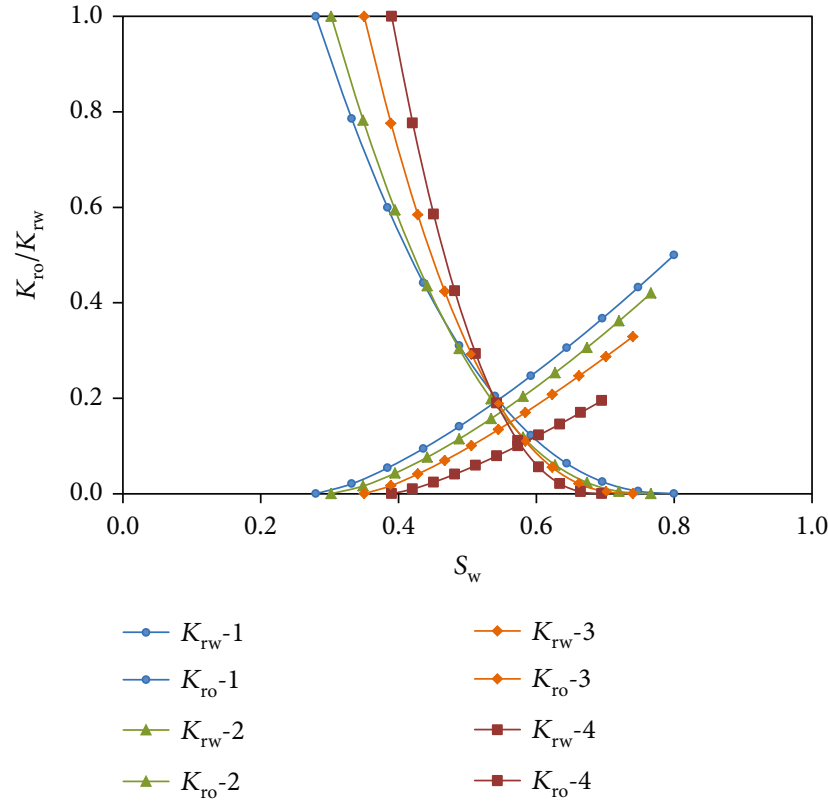

Figure 5: Relative permeability curves for different RRT.

reaching the same water saturation, resulting in a higher water cut increasing rate

(ii) Dimensionless oil production index changing law: the dimensionless oil production index decreases with water cut increase (see Figure 7). The worse the physical property of the reservoir, the lower the dimensionless oil index under the same water cut; i.e., the faster the dimensionless oil index falls

(iii) Dimensionless liquid production index changing law: the dimensionless liquid production index decreases first and then increases. The worse the physical property, the lower the dimensionless liquid production index under the same water cut; i.e., the faster the dimensionless liquid production index decreases; the later the turning point from decreasing to increasing appears, the lower the maximum value of the dimensionless liquid production index; that is, the liquid production rate is difficult to increase in a low-permeability reservoir

(iv) The recovery of geological reserve changing law: the worse the physical property, the lower the recovery factor of reserves under the same water cut. The main reason is that the worse the physical property of the reservoir, the lower the movable oil in place (MOIP) and the higher the residual oil saturation, resulting in worse displacement effect

3.4. Comprehensive Seepage Law for Fluid Transporting in Reservoirs with Different Heterogeneity. The correlation between different micropore structure parameters and macroscopic seepage law has been analyzed. When the fluid flows through porous media during actual oilfield development, the macroscopic seepage law presents the superposition effect since different types of pores are coupled together. It is necessary to further discuss the superposition effect and superposition method of the seepage law when the fluid flows through different types of pores.

A numerical simulation case study was carried out to analyze the comprehensive seepage law under different heterogeneity. Taking the $\mathrm{X}$ oilfield as an example, a series of numerical simulation models are established. Nine injection wells and 16 production wells were set (see Figure 11) with the injection-production ratio of 1.0 .

Four models of different heterogeneity were established (see Table 2), the permeability of which all obeys the lognormal distribution with the same average permeability $(12 \mathrm{mD})$. The permeability distribution is completely random. Different permeability variations are used to characterize different degrees of heterogeneity. Also, the relative permeability curves of RRT- 1 to RRT- 4 are used when $K>$ $50 \mathrm{mD}, 10-50 \mathrm{mD}, 3-10 \mathrm{mD}$, and $K<3 \mathrm{mD}$, respectively, design cases of the four heterogeneous models (see Table 3 ).

The relationship curves of recovery, water cut, and water cut rising rate for different RRT and different heterogeneity cases are shown in Figures 12-14. It could be concluded that the higher the heterogeneity, the earlier the peak water cut rising rate. When the permeability variation is lower than 0.9 , the seepage law of heterogeneous reservoirs is between RRT-2 and RRT-3. When the permeability variation is higher than 0.9 , the seepage law gradually approaches RRT-4. It is indicated that the overall seepage law is close to that of the poor-property rock type as the heterogeneity strengthens.

3.5. Superposition Method of Seepage Law for Fluid Transporting through Different Rock Type Formation. Seepage law of fluid transporting through different RRT and the comprehensive superposition effect of different RRT were discussed. It is necessary to study the superposition method of fluid transporting through different rock type reservoirs. 


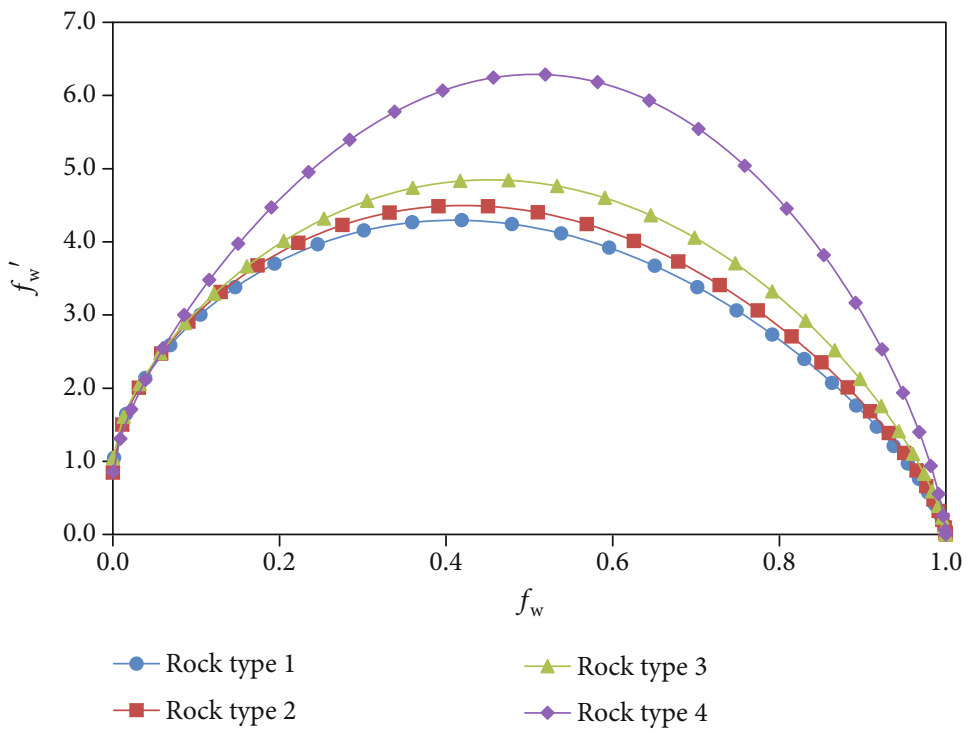

FIGURE 6: Relationship curves of the water cut rising rate and water cut for different RRT.

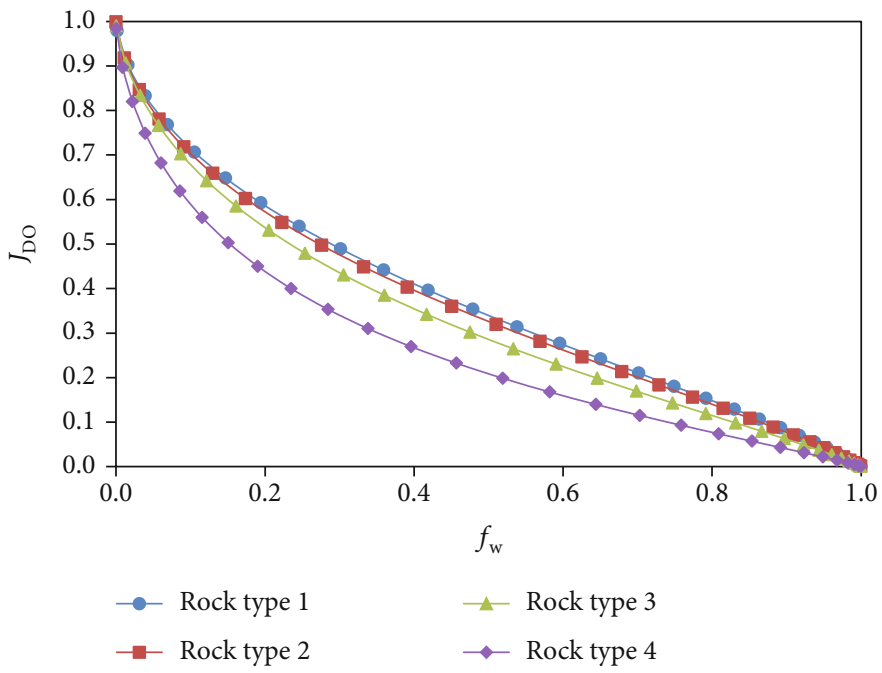

FIgURE 7: Relationship curves of the dimensionless oil production index and water cut for different RRT.

Three kinds of superposition method were discussed as follows.

3.5.1. Normalization Method. The normalization method is the most commonly used method, and the main idea is to calculate the average relative permeability curves. Assume that the RRT could be divided into $i$ categories.

$$
\begin{aligned}
& \overline{n_{\mathrm{w}}}=\frac{n_{\mathrm{w} 1}+n_{\mathrm{w} 2}+\cdots+n_{\mathrm{w} i}}{i}, \\
& \overline{n_{\mathrm{o}}}=\frac{n_{\mathrm{o} 1}+n_{\mathrm{o} 2}+\cdots+n_{\mathrm{o} i}}{i} .
\end{aligned}
$$

The other relative permeability parameters like $S_{\text {or }}, S_{\text {wi }}$, and $K_{\mathrm{rw}}\left(S_{\mathrm{or}}\right)$ should also be calculated through the same average method.
3.5.2. Reserve Weighted Average Method. Theoretically speaking, the normalization method based on arithmetic average is only applicable to the reservoir with weak heterogeneity. Obviously, if reservoir heterogeneity is strong, the normalized phase permeability based on arithmetic average would weaken the influence of heterogeneity on the development index. Therefore, it is necessary to discuss the new superposition method to reflect the influence of heterogeneity. Since the proportion of reserves of each rock type is usually different, the superposition method based on the reserve proportion is discussed first. The relationship of the water cut and recovery degree of each RRT could be obtained. Then, the comprehensive water cut and recovery degree relationship for the heterogeneous reservoir could be calculated according to the reserve ratio of each RRT.

$$
f_{\mathrm{R}}=f_{\mathrm{R} 1} N_{1}+f_{\mathrm{R} 2} N_{2}+\cdots+f_{\mathrm{R} i} N_{i} \text {. }
$$




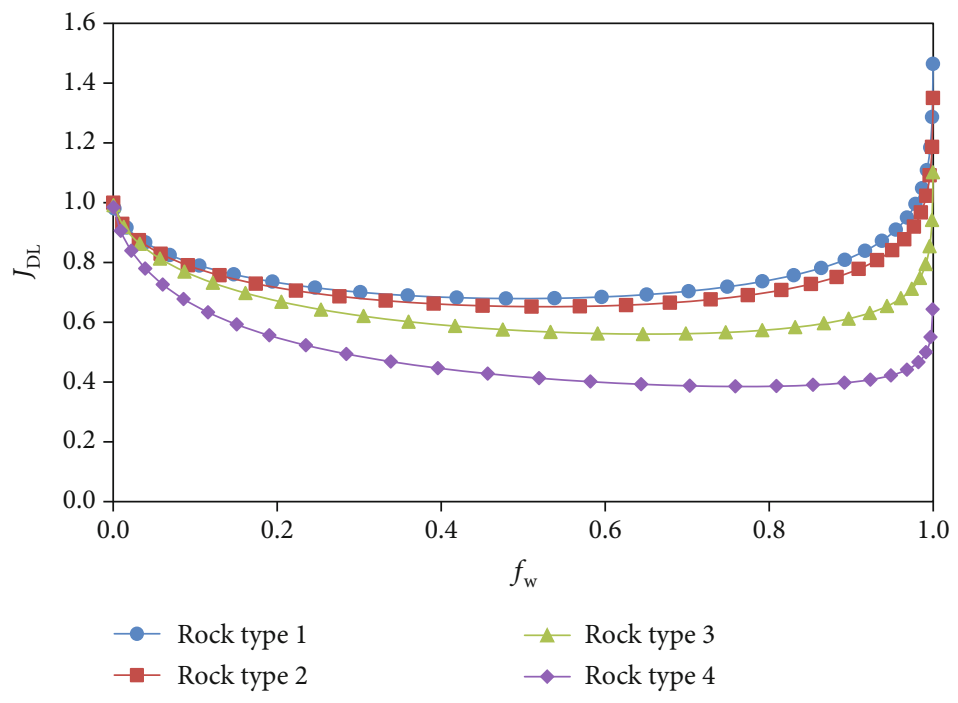

FIGURE 8: Relationship curves of the dimensionless liquid production index and water cut for different RRT.

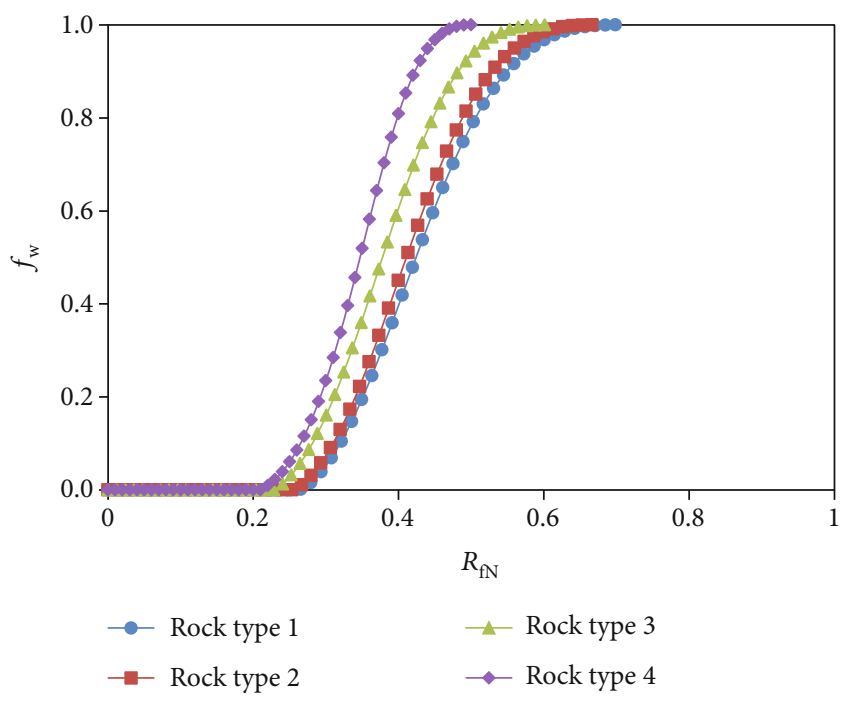

FIGURE 9: Relationship curves of the water cut and recovery degree for different RRT.

3.5.3. Improved Reserve Weighted Average Method. Obviously, if the heterogeneity is very strong, the abovementioned superposition methods are not satisfactory. The stronger the heterogeneity, the closer the seepage law after superposition to the poor reservoir law. Because this phenomenon is mainly caused by the heterogeneity degree, it is considered to add a heterogeneity coefficient $C$ to the superposition Equation (21).

$$
f_{\mathrm{R}}=\left(1-N_{2}-\cdots-C N_{i}\right) f_{\mathrm{R} 1} N_{1}+f_{\mathrm{R} 2} N_{2}+\cdots+C f_{\mathrm{R} i} .
$$

Through numerical simulation case studies, the relationship between the heterogeneity coefficient $C$ and permeability variation could be obtained as follows:

$$
C=0.7024 e^{1.1545 V_{K}}
$$

According to the research results of Luo and Wang and Zhang et al. [7, 8], the permeability variation could be calculated under the lognormal distribution of permeability as follows:

$$
V_{K}=\frac{\bar{K}-K_{84.1}}{\bar{K}} .
$$

This correlation is widely used for the calculation of permeability variation, with the range of $V_{K}$ between $[0,1]$. Therefore, the water cut rising law of different heterogeneous reservoirs could be predicted based on permeability variation.

Using the above numerical simulation results, the reliability of the reserve weighted average method could be verified. According to the water cut and recovery relationship curve of the four RRT models and reserve ratios of different heterogeneous models, the superposition water cut and recovery degree relationship curves were calculated (Figure 15). It was found that when the permeability variation is less than 0.7 , the superposition results are very similar to the numerical simulation results (see Figures 15(a) and $15(b))$. When the permeability variation is higher or equal to 0.7 , the superposition results are quite different from the numerical simulation results (see Figures 15(c) and 15(d)).

Thus, when the reservoir permeability variation is higher than 0.7 , a heterogeneity coefficient $C$ should be considered to be introduced (see Equation (26)). By fitting the calculation results to the above numerical simulation results, the relationship of the heterogeneity coefficient $C$ and permeability variation could be obtained, as shown in Figure 16.

It is observed that when the heterogeneity is weak $\left(V_{K}\right.$ is less than or equal to 0.7 ), the reserve weighted average method and normalization method can be used. When the heterogeneity is relatively strong $\left(V_{K}\right.$ is greater than or equal to 0.7 ), the improved reserve weighted average method is recommended.

3.5.4. Field Case Study. Continue taking the X oilfield as an example. The calculation result of permeability variation of 


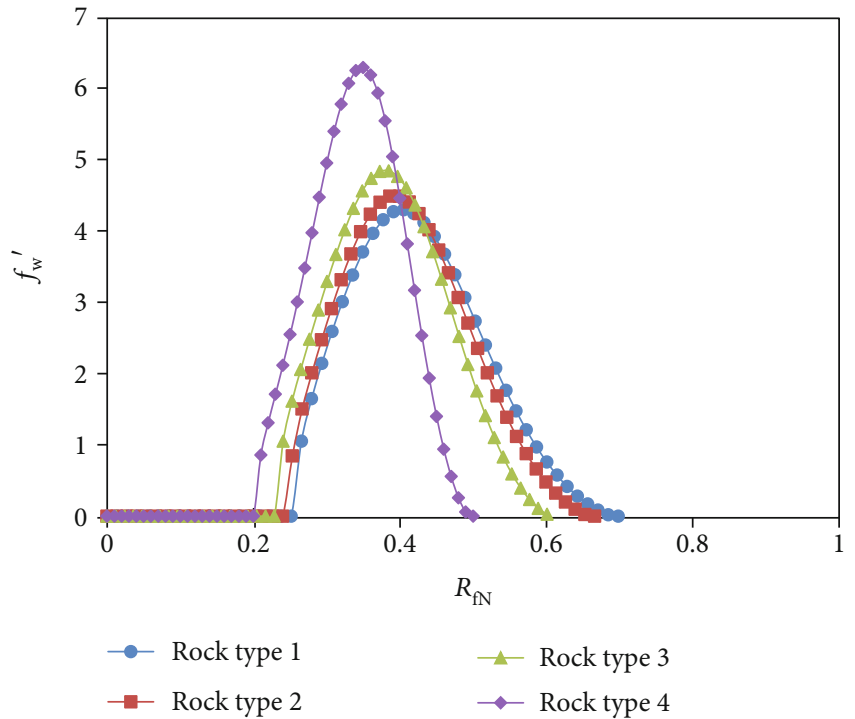

FIGURE 10: Relationship curves of the water cut rising rate and recovery degree for different RRT.

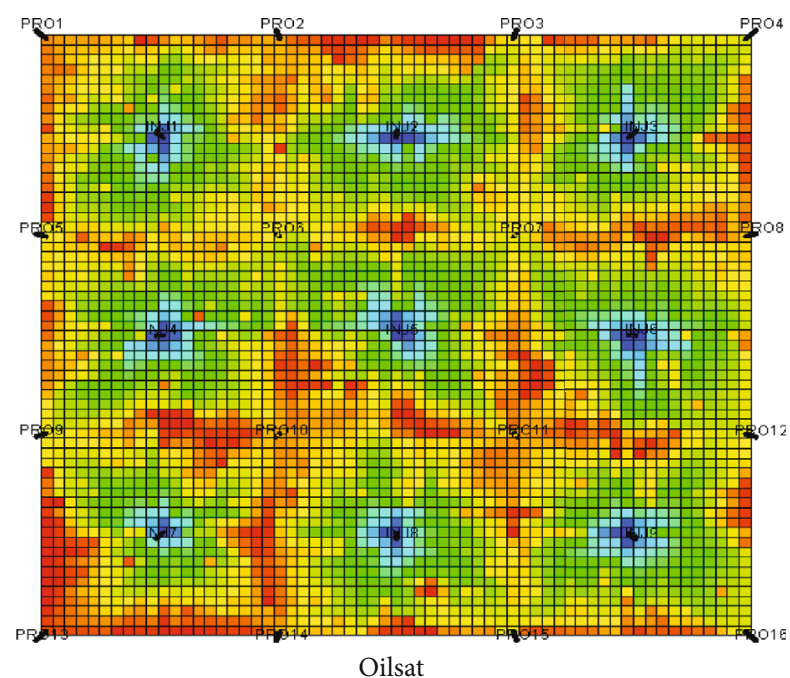

FIGURE 11: Top view of the single-layer five-spot mechanism model.

TABLE 2: Case design of the four RRT models.

\begin{tabular}{cccc}
\hline No. & $\begin{array}{c}\text { Scheme } \\
\text { name }\end{array}$ & $\begin{array}{c}\text { Relative } \\
\text { permeability curves }\end{array}$ & Permeability \\
\hline 1 & RRT-1 & RRT-1 & $\begin{array}{c}\text { Homogeneous model, } K \\
=636 \mathrm{mD}\end{array}$ \\
2 & RRT-2 & RRT-2 & $\begin{array}{c}\text { Homogeneous model, } K \\
=15.3 \mathrm{mD}\end{array}$ \\
3 & RRT-3 & RRT-3 & $\begin{array}{c}\text { Homogeneous model, } K \\
=4.24 \mathrm{mD}\end{array}$ \\
4 & RRT-4 & RRT-4 & $\begin{array}{c}\text { Homogeneous model, } K \\
=1.53 \mathrm{mD}\end{array}$ \\
\hline
\end{tabular}

reservoir $\mathrm{X}$ is 0.96 , indicating the strong heterogeneity. Then, the heterogeneity coefficient $C$ could be calculated using Equation (27). Also, according to Table 3, the reserve ratio
TABLE 3: Design scheme of heterogeneous models.

\begin{tabular}{ccccccc}
\hline No. & $\begin{array}{c}\text { Scheme } \\
\text { name }\end{array}$ & $\begin{array}{c}\text { Permeability } \\
\text { variation }\end{array}$ & $N_{1}$ & $N_{2}$ & $N_{3}$ & $N_{4}$ \\
\hline 1 & $V_{K}=0.5$ & 0.5 & 0.005 & 0.621 & 0.366 & 0.009 \\
2 & $V_{K}=0.6$ & 0.6 & 0.021 & 0.595 & 0.365 & 0.019 \\
3 & $V_{K}=0.7$ & 0.7 & 0.050 & 0.550 & 0.346 & 0.054 \\
4 & $V_{K}=0.8$ & 0.8 & 0.094 & 0.478 & 0.329 & 0.099 \\
5 & $V_{K}=0.9$ & 0.9 & 0.169 & 0.380 & 0.280 & 0.171 \\
6 & $V_{K}=0.94$ & 0.94 & 0.196 & 0.363 & 0.259 & 0.182 \\
7 & $V_{K}=0.96$ & 0.96 & 0.218 & 0.318 & 0.243 & 0.221 \\
8 & $V_{K}=0.98$ & 0.98 & 0.249 & 0.310 & 0.211 & 0.231 \\
9 & $V_{K}=0.99$ & 0.99 & 0.262 & 0.274 & 0.196 & 0.267 \\
\hline
\end{tabular}

Notes: (1) relative permeability curves of RRT-1 to RRT-4 are used when $K>50 \mathrm{mD}, 10-50 \mathrm{mD}, 3-10 \mathrm{mD}$, and $K<3 \mathrm{mD}$, respectively. (2) The permeability of the above-mentioned nine models all obeys the lognormal distribution with the same average permeability $(12 \mathrm{mD})$.

of the four RRT are $8 \%, 44 \%, 34 \%$, and $14 \%$, respectively. Based on the theoretical water cut and recovery relationship curves of each RRT, the superimposed water cut and recovery degree relationship curves could be predicted, as shown in Figure 17. Compared with the normalization method and reserve weighted average method, the predicted water cut rising rate of the improved method is higher, which is closer to the actual production data. It is also verified that the proposed superposition method is more suitable for strongly heterogeneous reservoirs.

3.6. Application Suggestions. The following are based on the above analysis:

(1) Based on microstructure characteristics, pore types, diagenesis, and genetic mechanism analysis, the influence of multiple factors is comprehensively taken into account, including the inheritance relationship between lithology and sedimentary facies belt, modification effects of diagenesis, and differences in diagenesis degrees related to different rock types in various sedimentary facies belts, and RRT could be divided into different categories through the quadrant element method, considering the inheritance relationship between the lithology and sedimentary facies belt. The quadrant element method takes more comprehensive factors into consideration, which could be used as a recommended method for RRT

(2) The water cut, water cut increasing rate, dimensionless oil/liquid production index, and recovery degree calculation models have systematically been proposed, presenting a quantitative relationship between micropore structure parameters and macroscopic seepage law. The analytical models could be used for predicting the dynamic performance and production profile. In fact, the newly proposed models clearly established and presented the influence of 


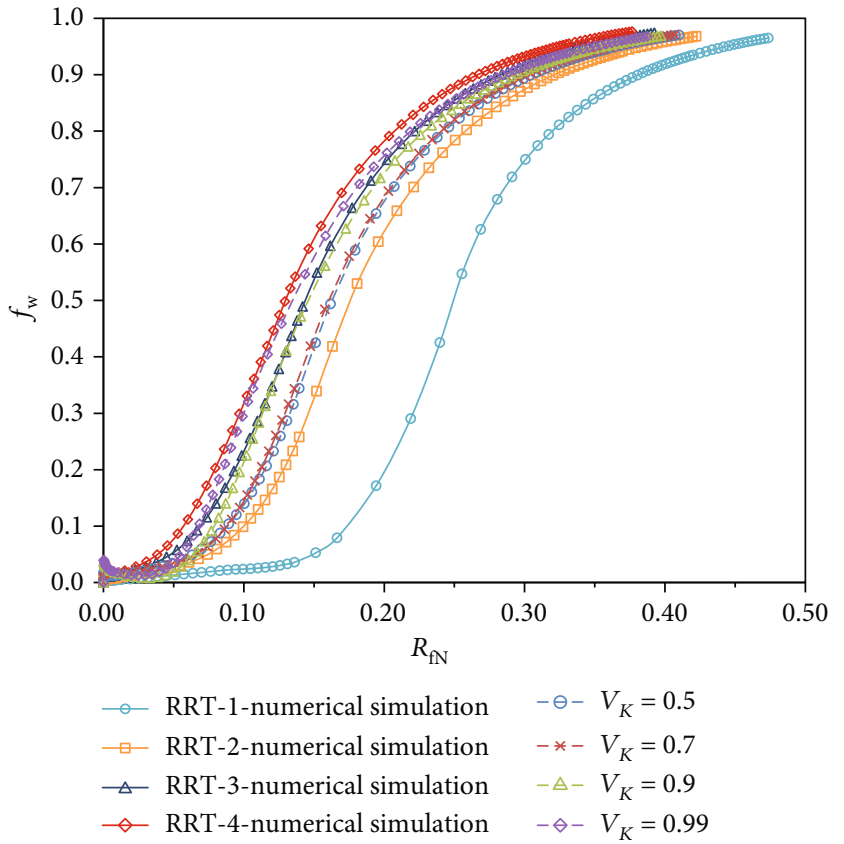

FIGURE 12: Relationship curve of the water cut and recovery degree for different heterogeneity cases.

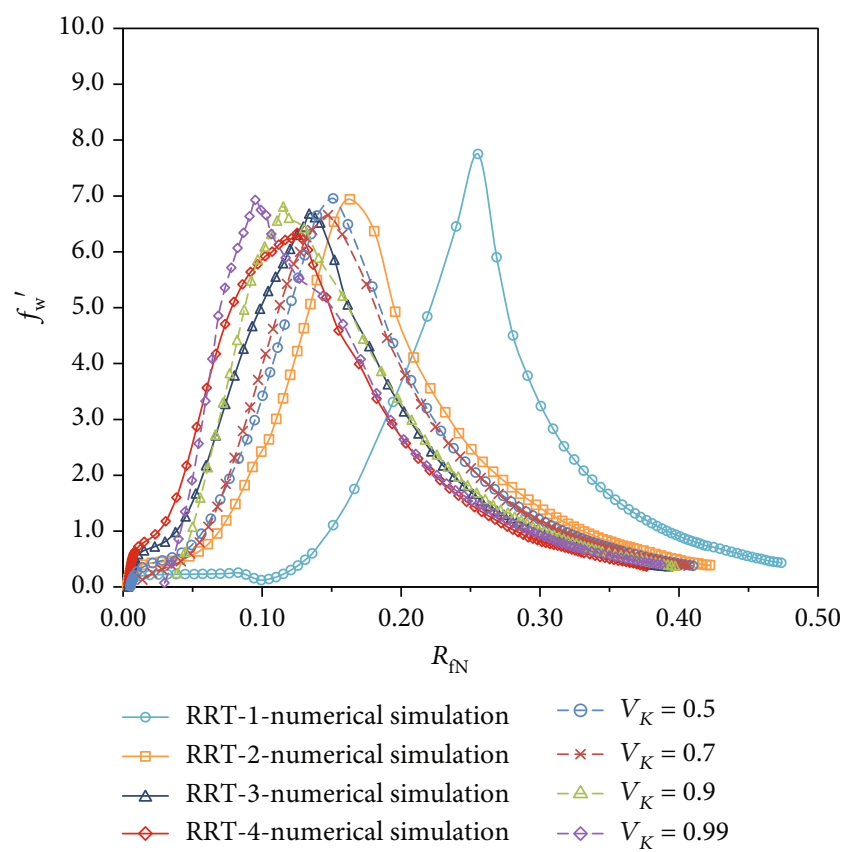

Figure 13: Relationship curve of the water cut rising rate and recovery degree for different heterogeneity cases.

micropore structure parameters on macroseepage law for the first time and show the influence degree of different micropore structures on macroseepage law

(3) As mentioned above, the commonly used normalization method is only applicable to relatively homoge-

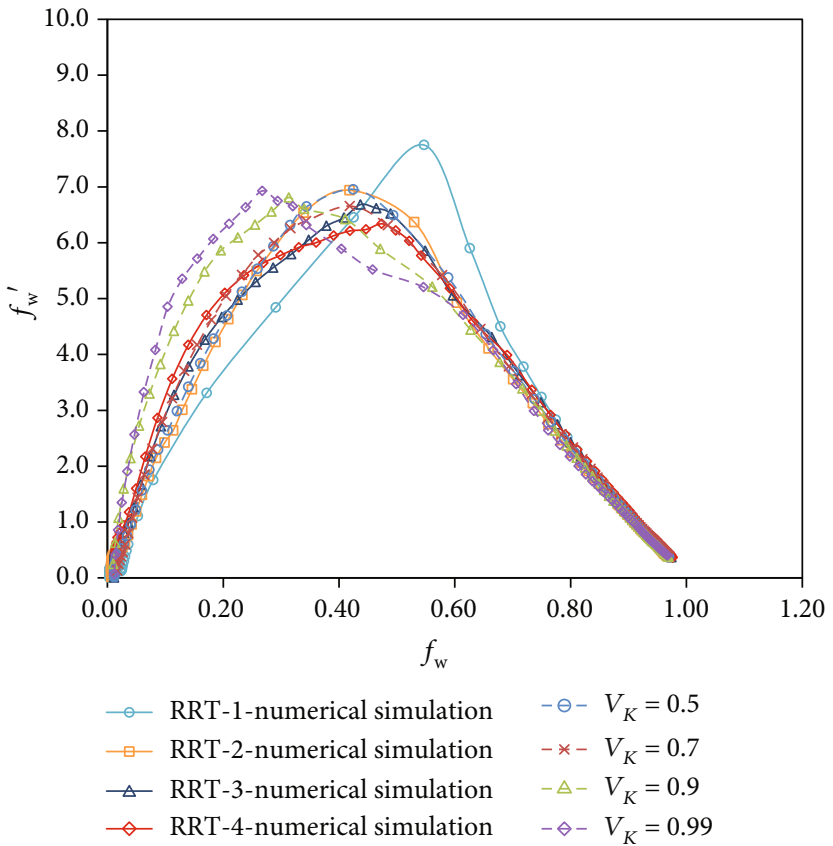

FIgURE 14: Relationship curve of the water cut rising rate and water cut for different heterogeneity cases.

neous reservoirs. It is clarified by analyzing the macroscopic seepage law under different heterogeneity degrees, when the coefficient of heterogeneity is greater than or equal to 0.7 , and the normalization method may cause optimistic estimates of the production profile. In such case, RRT should be classified and different relative permeability curves should be given for different rock types, which clarified the application conditions for the normalization method. Through theoretical research and sensitivity case analysis, the applicable conditions of the normalization method was clarified for the first time, which could effectively avoid the optimistic prediction of the production profile caused by simple normalization

(4) At present, many reservoir engineering methods predict the production profile on the basis of relative permeability curves. A superposition method considering the heterogeneity degree was proposed in this paper, which was verified to have high accuracy through an oilfield example. However, it needs to be clear that the superposition method could be used for the superposition of the relationship between the water cut and recovery degree, but the greater the degree of heterogeneity, the higher the peak of decline rate and water cut rising rate, which could be not characterized by a simple superposition

(5) Based on the analysis of the change rule of seepage law of different RRT, the influence of heterogeneity on macroscopic seepage law should be fully 


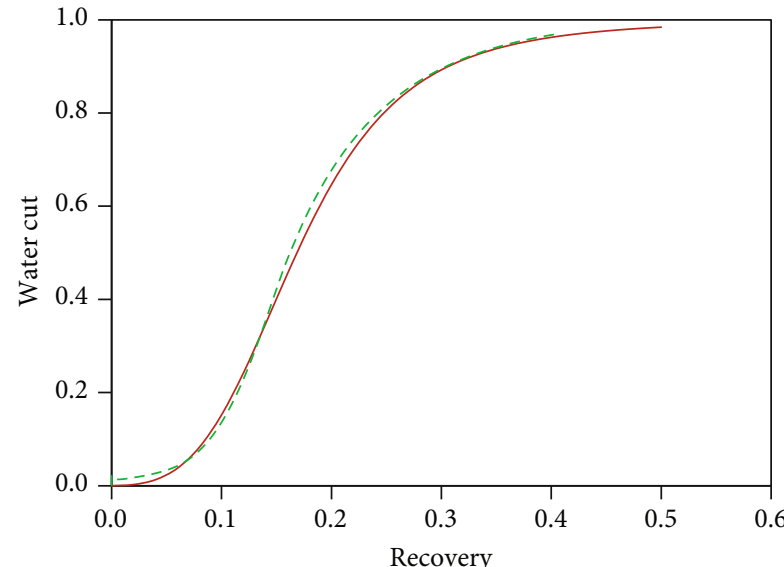

_ Reserve weighted average method - - Numerical simulation result

(a) $V_{K}=0.6$

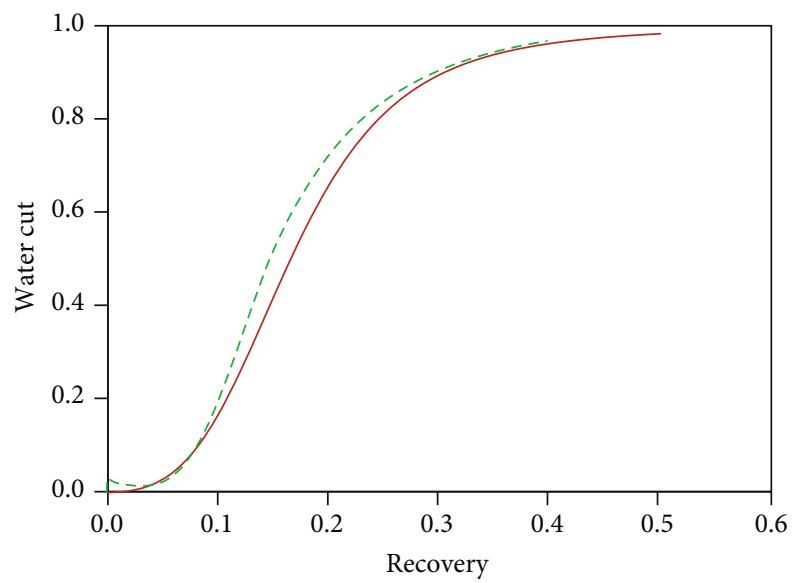

_ Reserve weighted average method

- - Numerical simulation result

(c) $V_{K}=0.8$

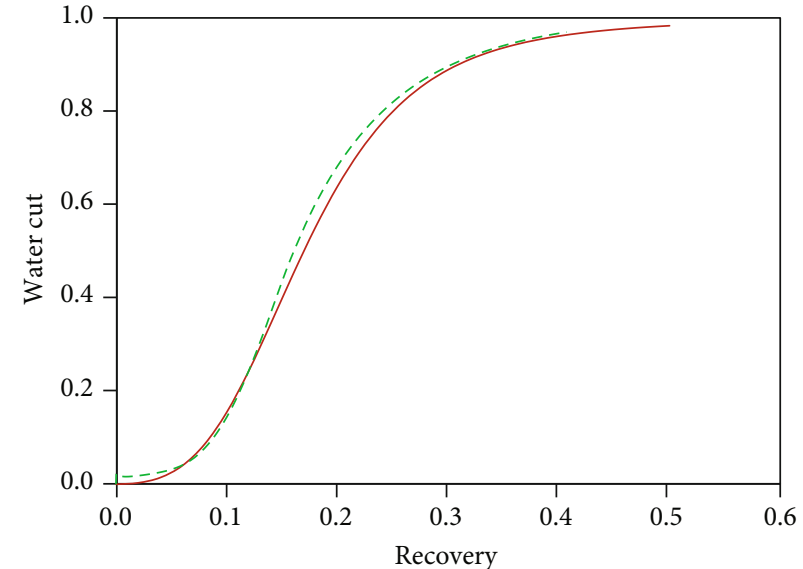

_ Reserve weighted average method

-. - Numerical simulation result

(b) $V_{K}=0.7$

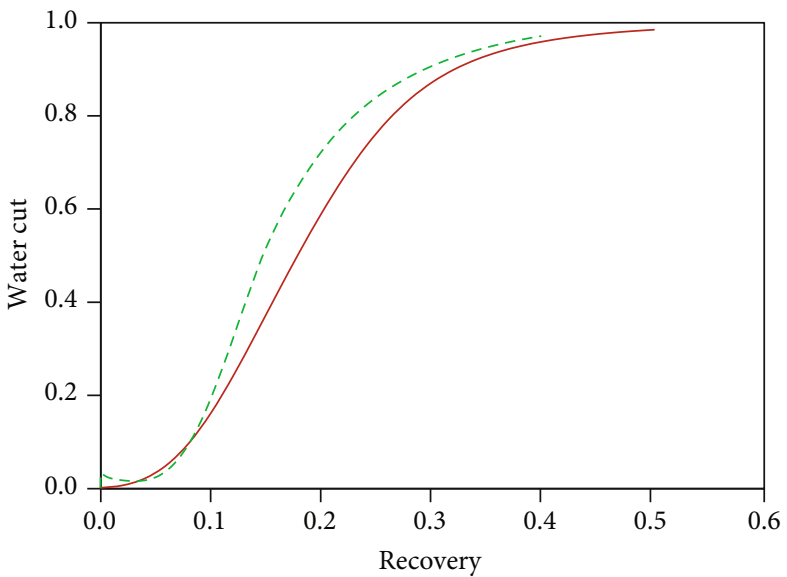

- Reserve weighted average method

- - - Numerical simulation result

(d) $V_{K}=0.96$

FIGURE 15: Comparison of the water cut and recovery relationship curve.

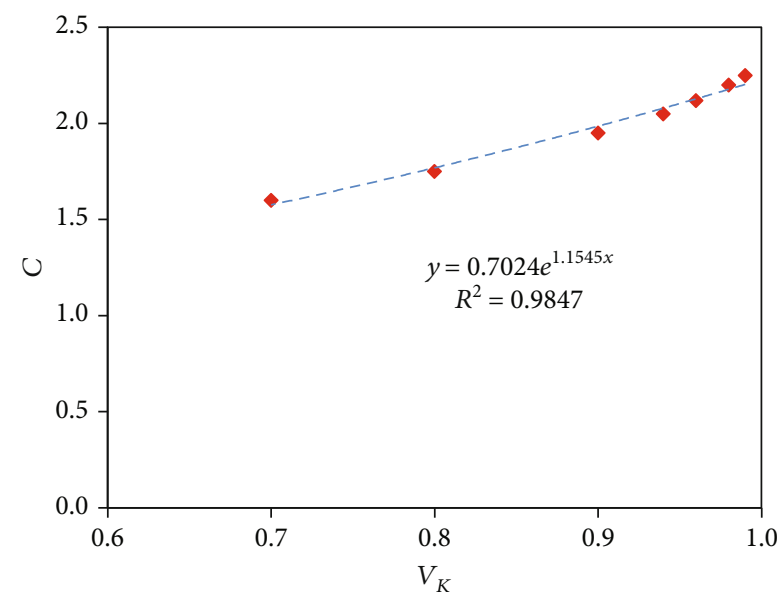

Figure 16: The relationship of the heterogeneity coefficient $C$ and permeability variation. considered while designing the well pattern, and different strategies should be adopted in different stages to further improve the development effect

(6) Formation damage is a common phenomenon during oil and gas field development. The micropore structure does change gradually in the process of formation damage, which leads to the change of reservoir physical parameters, wettability, and relative permeability curves. The process of formation damage can actually be regarded as the process of poor formation changing to good formation. The new analytical models proposed in this paper can reflect the influence of different formation damage degrees on macroscopic seepage law from a static point of view. It has a certain reference value for improving the prediction accuracy of the production profile and improving the development effect 


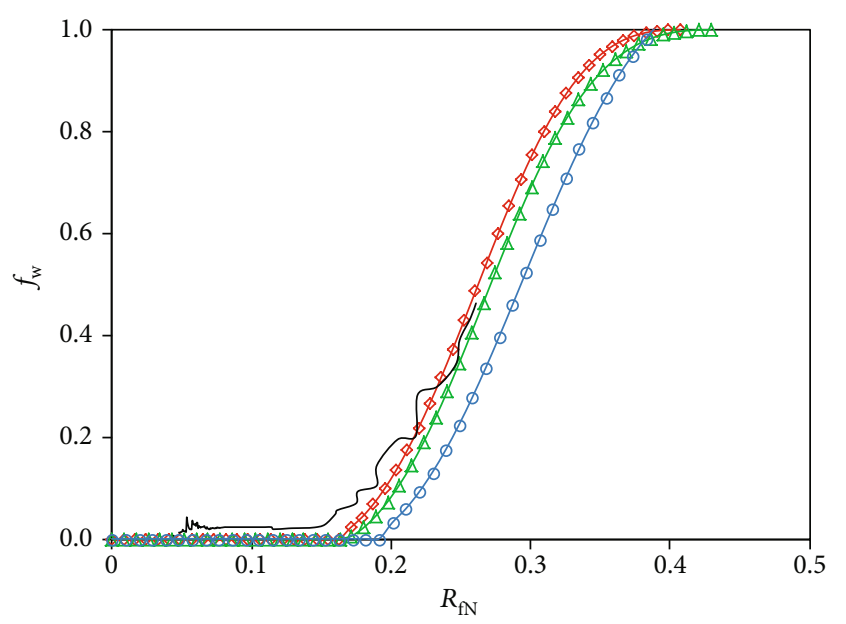

$\neg$ Improved reserve weighted method

$\triangle$ Normalization method

$\rightarrow$ Reserve weighted average method

_ Actual data

FIGURE 17: The predicted superimposed water cut and recovery relationship curves of the $\mathrm{X}$ oilfield.

\section{Conclusions}

(1) For strongly heterogeneous reservoirs, RRT could be divided into several categories through the quadrant element method, with factors considered comprehensively. For different RRT, there are significant differences in pore-throat characteristics, flow zone index (FZI), and relative permeability curves, indicating the internal unity of micropore structure and macroscopic seepage law

(2) The theoretical models for macroscopic seepage law were proposed. Results show that the water cut rises faster in poor-property rocks than in good-property rocks, with a lower recovery degree under the same conditions. The water cut rising rate increases firstly and then decreases with water cut and recovery degree rising, showing a peak water cut rising rate during the middle term. The poorer property the rock has, the earlier and higher the peak value is

(3) The comprehensive seepage law of fluid transporting through different rock types was analyzed. The higher the heterogeneity is, the earlier the peak point of water cut rising rate comes. When the permeability variation is lower than 0.9 , the water cut rising law of heterogeneous reservoirs is consistent with that of the medium rock type formation. When the permeability variation is higher than 0.9 , the water cut incremental law gradually approaches that of poor rock type formation

(4) When the heterogeneity is relatively strong $\left(V_{K}\right.$ is equal or greater than 0.7), the improved reserve weighted average method is recommended to better predict the actual incremental law of the water cut. It was clarified for the first time that the commonly used normalization method of relative permeability curves is only applicable to the relatively homogeneous reservoirs

\section{Nomenclature}

$K: \quad$ Reservoir permeability

$K_{\mathrm{rw}}\left(S_{\mathrm{or}}\right)$ : Relative permeability of water in residual oil saturation

$\phi: \quad$ Reservoir porosity

$K_{\text {ro }}\left(S_{\text {wi }}\right)$ : Relative permeability of oil in irreducible water saturation

$K_{\mathrm{rw}}$ : Water phase relative permeability

$S_{\text {or }}$ : Residual oil saturation

$K_{\text {ro }}$ : Oil phase relative permeability

$S_{\mathrm{wi}}: \quad$ Irreducible water saturation

$S_{\mathrm{wd}}$ : $\quad$ Proportion of movable water to fluid at the outlet

$\mu_{\mathrm{o}}$ : $\quad$ Viscosity of the oil phase

$\bar{S}_{\mathrm{w}}: \quad$ Average water saturation

$\mu_{\mathrm{w}}$ : Viscosity of the water phase

$B_{\mathrm{o}}$ : $\quad$ Volume coefficient of oil

$R_{\mathrm{f}}$ : Recoverable oil recovery

$B_{\mathrm{w}}$ : Volume coefficient of water

$E_{\mathrm{A}}: \quad$ Areal sweep efficiency

$\omega: \quad$ Welge function coefficient

$E_{Z}: \quad$ Vertical sweep efficiency

$N_{i}$ : $\quad$ Proportion of the reserves of the $i$-th RRT

$E_{\mathrm{D}}$ : Displacement efficiency

$V_{K}: \quad$ Permeability variation.

\section{Data Availability}

The data used to support the findings of this study are included within the article.

\section{Conflicts of Interest}

The authors declare that they have no conflicts of interest.

\section{Acknowledgments}

This work was supported by the Innovation Fund of China National Offshore Oil Corporation (CNOOC) (grant number CNOOC-KY-KJCX-CRI-2017-01) and the National Science and Technology Major Project (grant number 2017ZX05032-004).

\section{References}

[1] G. E. Archie, "Classification of carbonate reservoir rocks and petrophysical considerations," AAPG Bulletin, vol. 36, no. 2, pp. 278-298, 1952.

[2] A. Francesconi, F. Bigoni, P. Balossino, N. Bona, F. Marchini, and M. Cozzi, "Reservoir rock types application - Kashagan," in SPE/EAGE Reservoir Characterization and Simulation Conference held in Abu Dhabi, pp. 19-21, UAE, October 2009. 
[3] M. Mousavi, M. Prodanovic, and D. Jacobi, "New classification of carbonate rocks for process-based pore-scale modelling," SPE Journal, vol. 18, pp. 243-263, 2013.

[4] W. R. Purcell, "Capillary pressures-their measurement using mercury and the calculation of permeability therefrom," Journal of Petroleum Technology, vol. 1, no. 2, pp. 39-48, 2013.

[5] J. H. M. Thomeer, "Introduction of a pore geometrical factor defined by the capillary pressure curve," Journal of Petroleum Technology, vol. 12, no. 3, pp. 73-77, 2013.

[6] N. C. Wardlaw and R. P. Taylor, "Mercury capillary pressure curves and the interpretation of pore structure and capillary behavior in reservoir rocks," Bulletin of Canadian Petroleum Geology, vol. 24, no. 2, pp. 225-262, 1976.

[7] Z. T. Luo and Y. C. Wang, Pore structure of oil \& gas reservoir, Science and Technology Pres, Beijing, 1986.

[8] N. Zhang, F. Zhao, P. Guo et al., "Nanoscale pore structure characterization and permeability of mudrocks and finegrained sandstones in coal reservoirs by scanning electron microscopy, mercury intrusion porosimetry, and low-field nuclear magnetic resonance," Geofluids, vol. 2018, Article ID 2905141, 20 pages, 2018.

[9] J. A. Quiblier, “A new three-dimensional modeling technique for studying porous media," Journal of Colloid and Interface Science, vol. 98, no. 1, pp. 84-102, 1984.

[10] R. D. Hazlett, "Statistical characterization and stochastic modeling of pore networks in relation to fluid flow," Mathematical Geology, vol. 29, no. 6, pp. 801-822, 1997.

[11] P. E. Oren and S. Bakke, "Process based reconstruction of sandstones and predictions of transport properties," Transport in Porous Media, vol. 46, no. 2/3, pp. 311-343, 2002.

[12] B. Bai, R. Zhu, S. Wu et al., "Multi-scale method of nano(micro)-CT study on microscopic pore structure of tight sandstone of Yanchang Formation, Ordos Basin," Petroleum Exploration and Development, vol. 40, no. 3, pp. 329-333, 2013.

[13] V. Yakov and L. S. Win, "A practical approach to obtain primary drainage capillary pressure curves from NMR core and log data," Petrophysics, vol. 42, no. 4, pp. 334-343, 2001.

[14] X. P. LIU and X. X. HU, "Progress of NMR log in evaluating reservoir pore structure in the last five years," Progress in Geophysics, vol. 24, no. 6, pp. 2194-2201, 2009.

[15] G. Ni, H. Guo, X. Xu, and D. Huang, "Pore structure recognition and classification evaluation of complex carbonate reservoirs by using logging data: by taking $\mathrm{H}$ formation of an oilfield in the middle east for example," Journal of Oil and Gas Technology (Journal of Jianghan Petroleum Institute), vol. 36, no. 1, pp. 60-65, 2014.

[16] S. F. Jia, P. P. Shen, and K. W. Li, "Study in fractal characteristics and application of sandstone pore structure," Fault-Block Oil \& Gas Field, vol. 1, no. 2, pp. 16-21, 1995.

[17] L. Li, Y. Zhao, Z. Li, L. Liu, and Z. Xue, "Significance of fractal characteristics and fractal dimensions for micro-pore structure of porous media," Journal of the University of Petroleum, China, vol. 28, no. 3, pp. 105-108, 2004.

[18] P. Pfeifer and D. Avnir, "Chemistry in noninteger dimensions between two and three. I. Fractal theory of heterogeneous surfaces," The Journal of Chemical Physics, vol. 79, no. 7, pp. 3369-3558, 1983.

[19] A. J. Katz and A. H. Thompson, "Fractal sandstone pores: implications for conductivity and pore formation," Physical Review Letters, vol. 54, no. 12, pp. 1325-1328, 1985.
[20] C. Krohn, "Sandstone fractal and Euclidean pore volume distributions," Journal of Geophysical Research, vol. 93, no. B4, pp. 3286-3296, 1988.

[21] C. Krohn, "Fractal measurements of sandstones, shales, and carbonates," Journal of Geophysical Research, vol. 93, no. B4, pp. 3297-3305, 1988.

[22] R. F. Angulo, V. Alvarado, and H. Gonzalez, "Fractal dimensions from mercury intrusion capillary tests," in SPE Latin America Petroleum Engineering Conference, Caracas, Venezuela, 1992.

[23] W. He, F. Zhong, C. He, and W. Feng, "Fractal texture research on the pores in reservoir rocks and its application," Natural Gas Industry, vol. 20, no. 2, pp. 67-70, 2000.

[24] H. Huang, L. Chen, W. Sun et al., "Pore-throat structure and fractal characteristics of Shihezi Formation tight gas sandstone in the Ordos Basin, Chinavol. 26, Article ID 1840005.

[25] M. J. Chen, L. Cheng, and T. Lu, "Pore structure characterization and its impact on waterflooding development in Khasib reservoir in Ahdeb Oilfield, Iraq," Lithologic Reservoir, vol. 32, no. 3, pp. 132-143, 2020.

[26] H. Y. Liu, Z. Y. Tian, and Z. Y. Xu, "Quantitative evaluation of carbonate reservoir pore structure based on fractal characteristics," Lithologic Reservoir, vol. 29, no. 5, pp. 97-104, 2017.

[27] H. Y. Liu, Z. Y. Tian, and B. Liu, "Classification and prediction of giant thick strongly heterogeneous carbonate reservoir in the Middle East area: a case study of mid-Cretaceous Mishrif Formation in the W oilfield of Iraq," Acta Petrolei Sinica, vol. 40, no. 6, pp. 677-691, 2019.

[28] G. Perez and A. K. Chopra, "Evaluation of fractal models to describe reservoir heterogeneity and performance," SPE Formation Evaluation, vol. 12, pp. 65-72, 1997.

[29] S. D. Crane and K. M. Tubman, "Reservoir variability and modelling with fractals," in SPE Annual Technical Conference and Exhibition, pp. 23-26, New Orleans, Louisiana, September 1990.

[30] J. J. Li, Y. Liu, and Y. J. Gao, "Effects of microscopic pore structure heterogeneity on the distribution and morphology of remaining oil," Petroleum Exploration and Development, vol. 45, no. 6, pp. 1112-1122, 2018.

[31] P. Li, W. Sun, and J. Yan, "Microscopic pore structure of Chang 63 reservoir in Huaqing oilfield, Ordos Basin, China and its effect on water flooding characteristics," Journal of Petroleum Exploration and Production Technology, vol. 8, no. 4, pp. 1099-1112, 2018.

[32] P. Li, W. Sun, Z. Wang, H. Huang, and W. Zhe, "Features of microscopic pore structure and their influence on oil displacement efficiency in Chang 81 reservoir of Xifeng oilfield, Ordos Basin," Geoscience, vol. 32, no. 6, pp. 1194-1202, 2018.

[33] H. X. Liu, C. F. Xu, and J. H. Qin, "Pore structure and oil drainage efficiency of conglomerate reservoir," Journal of Oil and Gas Technology, vol. 32, no. 4, pp. 189-191, 2010.

[34] Z. Cai, "Study on relationship between pore structure and displacing oil efficiency," Petroleum Exploration and Development, vol. 27, no. 6, pp. 45-46, 2000.

[35] M. G. Lu and X. L. Tong, "Characteristics of pore structures and oil production potential of sandstone reservoir of Paleogene Xingouzui Formation in Jianghan basin," Petroleum Geology and Oilfield Development in Daqing, vol. 26, no. 4, pp. 31-34, 2007. 
[36] J. Li, Y. Li, and C. C. Zhou, "Effect of pores structure parameter on polymer flooding recovery-applying 3D porosity network model," Petroleum Geology and Oilfield Development in Daqing, vol. 28, no. 3, pp. 110-115, 2009.

[37] H. Wei, W. Sun, and L. Qu, "Micro-pore structure characteristics and its influence on gas well production performance in the norther part of sandstone reservoir in Jingbian gasfield," Geological Science and Technology Information, vol. 30, no. 2, pp. 85-90, 2011.

[38] Q. Y. Wang, Y. B. Bi, D. Y. Xiu, M. Z. Fang, and Y. H. Wang, "Research of reservoir and seepage law for complex block oilfield with special high water cut," Special Oil and Gas Reservoir, vol. 20, no. 4, pp. 70-73, 2013.

[39] S. E. Buckley and M. C. Leverett, "Mechanism of fluid displacement in sands," Transactions of the AIME, vol. 146, no. 1, pp. 107-116, 1942.

[40] J. Q. Zhang, Production prediction model for waterflooding reservoirs, Oil industry press, 2013.

[41] J. Q. Zhang and R. F. Yang, "A further study on Welge equation," Energy Exploration \& Exploitation, vol. 36, no. 5, pp. 1103-1113, 2018.

[42] H. Dykstra and R. L. Parsons, The Prediction of Oil Recovery by Waterflooding, Secondary Recovery of Oil in the United States, API, Dallas, 2nd edition, 1950.

[43] M. R. Fassihi, "New correlations for calculation of vertical converge and areal sweep efficiency," SPE Reservoir Engineering, vol. 1, pp. 604-606, 1986. 